\title{
A pesquisa sobre as escritas: um diálogo entre Linguística, Semiótica e Antropologia ${ }^{1}$
}

\author{
Isabelle Klock-Fontanille' \\ https://orcid.org/0000-0002-3803-6506 \\ I - CeReS, Université de Limoges \& IUF. \\ Limoges, França
}

Resumo: A pesquisa sobre as escritas permaneceu por muito tempo subordinada à Linguística, conforme uma concepção representativa-fonocêntrica simplista em que a escrita se encontrava submetida à língua. Essa posição é agora insustentável. Graças ao encontro entre Semiótica, Linguística e Antropologia, a pesquisa sobre as escritas foi renovada. A partir dos estudos das semióticas figurativas e plásticas, deu-se a reintrodução do imagético e a tomada de consciência da espacialidade no estudo das escritas. A abordagem antropológica indicou que a escrita e seus mecanismos apresentam um conjunto de valores culturais, sendo um meio privilegiado para a produção ideológica e simbólica de um povo. A linguística abriu-se assim a outras disciplinas, passando a considerar a escrita como um continuum pluri-semiótico que comporta intrinsecamente uma dimensão icônica e uma dimensão linguística.

Palavras-chave: escritas; pesquisa sobre escritas; Linguística; Semiótica; Antropologia.

Abstract: The research on writings: a dialogue between Linguistics, Semiotics and Anthropology - The research on writings remained for a long time subordinated to Linguistics, following a simplistic representative-phonocentric conception in which writing was subjected to language. This position is now unsustainable. Due to the encounter between Semiotics, Linguistics and Anthropology, the research on writings has been renewed. According to the studies of figurative and plastic semiotics, imagery has been reintroduced in the study of writings, as well as the awareness of spatiality. The anthropological approach has shown that writing and its mechanisms present a set of cultural values, being a privileged emplacement for the ideological and symbolic production of a society. Linguistics has therefore opened up to other disciplines, now considering writing as a pluri-semiotic continuum that comprises both an iconic dimension and a linguistic dimension.

Keywords: writings; research on writings; Linguistics; Semiotics; Anthropology.

1 Publicado originalmente em francês na revista Langages, n. 213 (1/2019), pp. 29-41, Armand Colin, com o título "La recherche sur les écritures : un dialogue entre linguistique, sémiotique et anthropologie". Disponível em: $<$ https://www.revues.armand-colin.com/lettres-langues/langages/langages-no-213-12019/recherche-ecrituresdialogue-entre-linguistique-semiotique-anthropologie>. 


\section{Introdução}

A pesquisa sobre as escritas permaneceu por muito tempo subordinada à Linguística, como uma espécie de "parente pobre" dessa disciplina: desde Aristóteles, para quem "as palavras escritas [são] os símbolos das palavras emitidas pela voz" (ARISTOTE, 1936, 16a), até F. de Saussure, para quem "língua e escrita são dois sistemas distintos de signos; a única razão de ser do segundo é representar o primeiro" (2006, p. 34). Mas foi sem dúvidas Lessing quem, em seu Laocoon (1766), canonizou a dicotomia entre língua e imagem, declarando o divórcio entre dizer e mostrar, representação e apresentação, discursivo e icônico. Partindo do pressuposto de que há uma divergência irredutível entre o discursivo e o icônico, a escrita é então considerada como a fala tornada visível e fixa: ela é uma linguagem verbal e não uma imagem. Essa concepção, que está na base dos trabalhos de numerosos linguistas e historiadores da escrita (FEVRIER, 1959; GELB, [1952] 1973), é a expressão da concepção tradicional da escrita: concepção fonocêntrica (a escrita como código segundo, destinado a representar a fala), teleológica (a escrita considerada como uma evolução até seu ponto culminante, o alfabeto) e etnocêntrica (superioridade do alfabeto grego, depois o latino, esse último sendo considerado como o sistema mais apropriado a representar tudo o que pode ser dito, transcrevendo os componentes sonoros da fala, os fonemas). Essa posição é agora insustentável. Graças ao encontro entre a Semiótica, a Linguística e a Antropologia, a pesquisa sobre as escritas encontra-se completamente renovada.

\section{Pondo em questão: a Semiótica}

O estudo de A. J. Greimas, publicado em 1984 em Actes Sémiotiques - Documents (VI, 60), intitulado "Semiótica figurativa e semiótica plástica", parece-nos fundador. Ele tem por objetivo constituir um novo campo de exploração, a semiótica visual, na qual A. J. Greimas inclui os diferentes tipos de escrita, as linguagens de representação gráfica. Mesmo que a escrita não seja o objeto do estudo, essa reflexão nos permitiu:

- levar em consideração o papel da imagem, que faz parte intrinsecamente da escrita. Essa reflexão é desenvolvida por conceitos como o de notational iconicity de N. Goodman ou o de Schriftbildlichkeit de S. Krämer (2003, 2016), mas também o de script de S. Battestini $(1997,2006)$;

- (re)colocar a questão das relações entre expressão e conteúdo, estabelecendo assim a escrita como um sistema semiótico, ou seja, questionando a visão simplesmente representativa da escrita. A escrita faz parte das linguagens em que não há conformidade entre os dois planos;

- considerar a escrita como uma linguagem planar, ou seja, introduzir a questão do espaço. Acima de tudo, segundo A. J. Greimas, se analisamos um objeto visual sobre o plano plástico, devemos estabelecer o "fechamento" desse mesmo objeto. 
Não é mero acaso que os primeiros trabalhos do que podemos chamar semiótica da escrita tenham sido realizados por africanistas e que esses primeiros trabalhos tenham prontamente mostrado que o diálogo com outras disciplinas era necessário, especialmente em torno das figurações icônicas (KLOCK-FONTANILLE, 2016a). O primeiro número da revista Semiotica, publicado em 1969, continha o dossiê "Semiótica na África". Podemos encontrar nele um artigo fundamental de G. Calame-Griaule e P.-F. Lacroix, "Grafismos e sinais africanos". A escrita, ou de maneira mais geral os sinais gráficos, estão ligados à linguagem verbal, mas não têm como única função representar a língua. Nesse estudo, os autores insistem também no fato de que uma das características definidoras fundamentais da escrita é a de que ela é ao mesmo tempo uma semiótica linguística e uma semiótica do espaço. Africanistas, como S. Battestini, desenvolveram esta concepção:

\begin{abstract}
A função da escrita não pode mais se limitar à notação da fala, tampouco à do pensamento indiretamente, mas é mais comumente percebida hoje como encarregada de arquivar e transmitir o pensamento organizado, do texto. Portanto, não se trata mais de escrita no sentido corriqueiro e etnocêntrico, mas de uma técnica, aquela da inscrição do sentido. (BATTESTINI, 2006, p. 24. Tradução nossa).
\end{abstract}

A escrita designa todos os modos gráficos e demais modos de conservação e de transmissão de saberes endógenos e mensagens, incluindo as escritas fonológicas, sintéticas e analógicas, assim como os objetos e as imagens cuja função social é similar. Para J. Battestini, a escrita não é mais considerada apenas sob o ângulo de sua relação com a língua, mas também em suas relações com a imagem.

A reintrodução da imagem e a consideração do espaço permitiram à Semiótica encontrar uma entrada para esse campo da escrita.

\title{
Antropologia: a escrita não diz respeito apenas à língua
}

A abordagem antropológica (CARDONA, 1981; SEVERI, 1994; PERRI, 2007, 2014) pôs em evidência que o ato escritural e seus mecanismos refletem não apenas a necessidade de transcrever uma língua, mas também um conjunto de valores culturais, de conhecimentos enciclopédicos, de manifestações ideológicas e de fins econômicos e administrativos. A escrita é assim não apenas uma grande invenção técnica, mas também o local privilegiado para a produção ideológica e simbólica: significados diversos (políticos, religiosos etc.) atualizam-se nas expressões. É o que podemos ler já no estudo de A. J. Greimas citado acima: "a escrita apresenta-se como um dispositivo visual articulado, apto a representar qualquer coisa (o universo semântico em sua totalidade)" (1984, p. 22).

G. R. Carona mostra igualmente que a plena compreensão daquilo que ele chama de "função gráfica do signo" foi por muito tempo dificultada pela ideia preconcebida de que toda análise da escrita deveria partir da codificação linguística. Pelo contrário, 
a função gráfica deve ser considerada como um sistema de modalização primário do pensamento - o que A. J. Greimas chamava "o universo semântico em sua totalidade". Os signos empregados pelos sistemas hieroglíficos podem, de fato, ter um valor fonético e igualmente transmitir significados e verdadeiros conteúdos culturais de modo direto, imediato - sem passar pela codificação linguística - graças ao potencial icônico que é próprio às escritas hieroglíficas. Para os antropólogos, a escrita não se limita assim a oferecer uma forma tangível às sequências efêmeras da língua, ela representa, com a língua, um dos instrumentos mais poderosos para compreender e manipular a realidade e para controlar a sociedade.

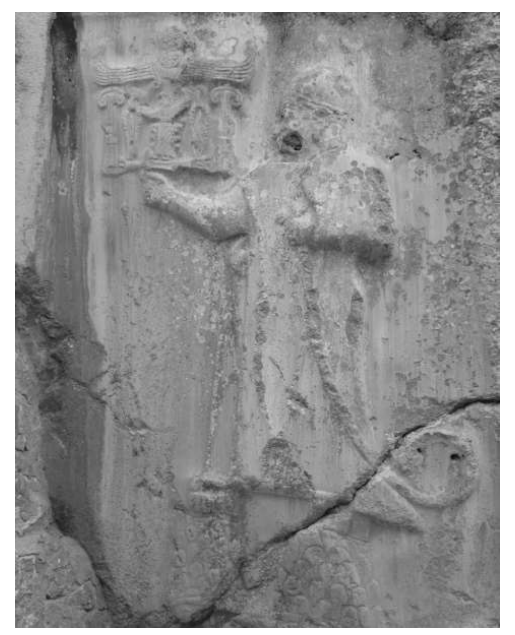

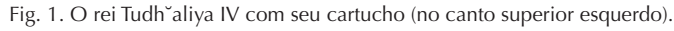
Fonte: a autora.

O exemplo acima (Fig. 1) permite-nos observar uma composição que mistura vários modos de expressão, podendo o mesmo elemento pertencer a diversas ordens (KLOCKFONTANILLE, 2006). A afinidade consubstancial da escrita e da imagem se manifesta particularmente na relação entre lenda e manifestação.

Assim, em Yazılıkaya (Turquia), santuário rupestre onde se encontra representado o panteão hurrita, podemos ver o rei hitita Tudh aliya IV (século 13 a.C.) representado com seu cartucho ${ }^{2}$ (Fig. 2). Ele escala duas montanhas (conferir os blocos de escamas na parte inferior da ilustração). Na verdade, ele está representado como o grande deus da tempestade Te`sub, sobre montanhas. O rei é até mesmo assimilado à montanha (personagem usando uma tiara de chifres e vestido com saia de escamas). Esse é justamente o sinal gráfico que ele

2 A escrita hieroglífica anatólia (nativa) coexistiu com a escrita cuneiforme (importada) no Império Hitita. Ela notava a língua luvita (uma língua indo-europeia prima do hitita-nesita) e era utilizada sobretudo na glíptica e em suportes monumentais (segunda metade do $2^{\circ}$ milênio até cerca de 700 a.C.). 
escolheu para o cartucho onde está inscrito seu nome, como vemos na ilustração (Fig. 2).

Essa escolha é bastante incomum. De fato, o sinal esperado (este é o caso no seu selo) consiste na ligadura de DEUS e de MONTANHA (bloco de escamas estilizado), como mostra a ilustração (Fig. 3).

O sinal funciona então como representação e como signo gráfico. E, como conhecemos os vínculos estreitos entre Tudh aliya IV e o deus Montanha devido às listas, vemos ainda melhor que a escrita comporta pictoricamente o significado linguístico de sua conotação ideológica.

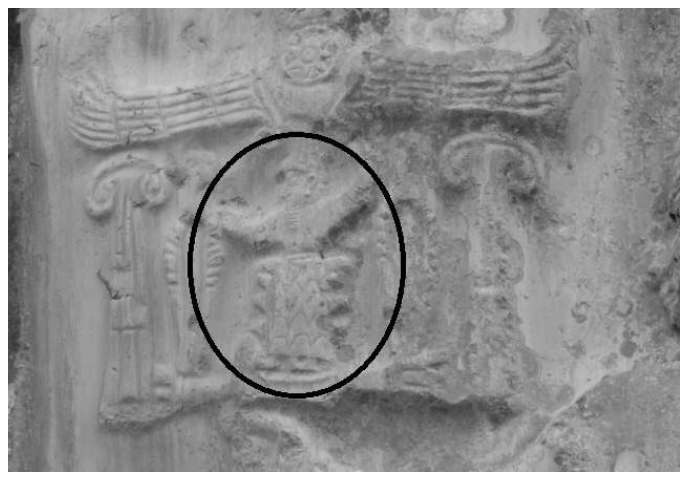

Fig. 2. O cartucho do rei Tudh `aliya IV - sob o sol alado, seu nome encontra-se no centro, cercado de cada lado pelo ideograma Labarna (título do rei em exercício) e LUGAL.GAL (Grande Rei). Fonte: a autora.

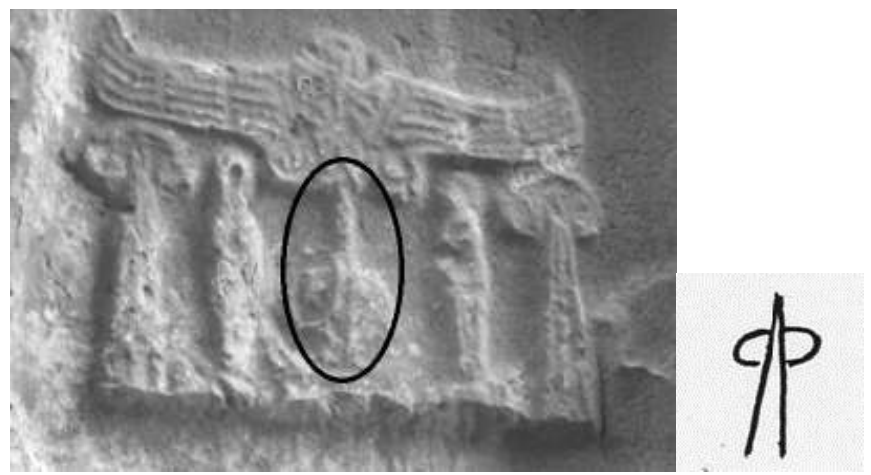

Fig.3. O cartucho do rei Tudh ăliya IV em outra representação em Yazılıkaya - seu sinal é formado pela ligadura MONTANHA + DEUS. Fonte: a autora.

Esse uso das potencialidades icônicas dos sinais hieroglíficos e/ou das potencialidades escriturais das imagens permite transgredir a separação entre o registro da escrita e o registro das representações: o mesmo elemento pode funcionar ao mesmo tempo como parte constituinte de uma inscrição (no caso, do cartucho) e parte constituinte de uma representação adjacente (o rei de pé sobre duas montanhas). 
No caso dos hieróglifos, portanto, nós não nos encontramos em uma situação onde há o texto de um lado e as imagens de outro. Os dois elementos parecem operar em harmonia: não apenas os glifos possuem uma natureza icônica, mas também os textos e as imagens que frequentemente os acompanham, nos relevos ou na glíptica, completam-se mutuamente: eles estão estreitamente ligados para oferecer um significado definido ao que foi gravado no suporte.

A escrita assume então duas famílias de funções: (i) funções glóssicas; neste primeiro caso, os signos escriturais têm como plano da expressão funções ou dados do código linguístico (essas são as únicas funções que, normalmente, o linguista leva em consideração segundo a concepção estrita de escrita); e (ii) funções gramatológicas: neste segundo caso, os signos gráficos não remetem às funções do código linguístico, mas assumem uma outra função semiótica possibilitada pela inscrição da escrita no espaço.

\section{Linguística: uma concepção revisitada da escrita}

Existe hoje uma desvalorização da abordagem linguística que reduz a escrita à sua função acessória. A pesquisa passou tempo demais prisioneira da visão representativafonocêntrica (e etnocêntrica) da escrita. Mas, desde que ela se liberou, ela teve tendência a esquecer uma característica intrínseca dessa última: certamente, a parte imagética é importante mas, ao mesmo tempo, o fonetismo sempre existiu, em coabitação e combinação com ela.

Mais precisamente, estamos em presença não de dois códigos distintos, mas de um continuum pluri-semiótico, de uma codificação híbrida que comporta intrinsecamente uma dimensão icônica e uma dimensão linguística (é essa característica da escrita que S. Krämer chama Schriftbildlichkeit). Essa vontade de redefinir o signo escrito e autonomizar o escritural foi alcançada pela abertura a outras disciplinas ou paradigmas de pesquisa, a fim de extrair argumentos capazes de assentar uma semiologia ou até mesmo uma linguística da escrita.

A partir da análise da concepção errônea de escrita como notação da fala que contaminou a Linguística, pesquisadores como R. Harris revisitaram essa abordagem e propuseram uma nova teoria semiológica geral baseada no signo em seu contexto. Em The origin of writing (HARRIS, 1986), ele estuda as condições do surgimento da escrita, considerada como uma invenção, cujo objetivo não era fixar a fala, mas implementar um novo suporte de comunicação. A escrita não é uma representação gráfica da fala, mas um sistema de representação de ideias (pensemos no "universo semântico" de A. J. Greimas) que possui sua autonomia. Uma notação gráfica pode difundir sentidos independentemente de ser a representação de uma palavra da língua falada.

R. Harris é, de certa forma, um discípulo de F. de Saussure, dado que esse queria estudar "a vida dos signos no seio da vida social", mas um discípulo infiel, já que ele 
constrói a sua "semiologia da escrita" a partir de uma crítica ao mestre genebrino e já que seu projeto é o de substituir a Semiologia de inspiração saussuriana por uma Semiologia geral que ele chama de "integrativa" (HARRIS; 1993, 1998). Essa se baseia no signo em seu contexto. O signo integrativo não tem existência autônoma e independente, ele é o produto criado pela integração de um certo número de atividades em certos contextos. A escrita é assim considerada como uma constelação intersemiótica:

A própria escrita pressupõe certas atividades sem as quais ela seria impossível. Trata-se, ressaltamos, não apenas de atividades pragmáticas mas também de atividades mentais ou cognitivas exercidas no contexto de uma situação social. (HARRIS, 1993, p. 20. Tradução nossa).

Para linguistas como R. Harris, a relação com a língua é secundária. Quanto à questão da relação língua-escrita, uma via bastante fecunda (e pouco reconhecida) foi aberta por É. Benveniste, em suas Últimas aulas (2014). Nas aulas 8 a 15, dedicadas à escrita, a questão essencial é a da relação língua-escrita. Longe de uma visão representativa que faria da escrita um código de articulação primária (um código no qual cada elemento do plano da expressão encontra um equivalente no plano do conteúdo), É. Benveniste pergunta-se como "repensar do zero, em sua relação primordial, a língua e a escrita" (2014, p. 127). Os três postulados são os seguintes: (i) existe uma relação língua-escrita; (ii) a relação língua-escrita é uma relação de conversão recíproca; (iii) a escrita é um sistema semiológico homogêneo e ligado ao sistema da língua: "não há relação necessária entre a língua e a escrita", escreve É. Benveniste (2014, p. 141). Porém, um pouco mais adiante, ele ressalta que "todos os problemas das relações entre a língua e a escrita são renovados se colocamos o seguinte princípio fundamental: a escrita é uma forma secundária da fala" (BENVENISTE, 2014, p. 177) e que a escrita é uma "linguagem visível" (BENVENISTE, 2014, p. 179).

Essa relação é estabelecida por procedimentos de conversão, de transposição: há duas referências à "súbita conversão da língua em imagem da língua" (BENVENISTE, 2014, p. 130).

Na esteira de pesquisadores como P. Vernus (1982, 1985, 1988, 2016), J.-J. Glassner (2000) ou M. Marazzi (2010, 2016), nós desenvolvemos (KLOCK-FONTANILLE, 2006, 2011) a ideia de que, partindo de uma mesma inscrição, duas percepções concorrentes contribuem juntas para a liberação de valores semióticos (linguístico vs. icônico) e mostramos como se articula a tensão entre duas valências perceptivas: de um lado, a identificação linguística e, de outro, o reconhecimento icônico. A escrita pertence, de maneira definitiva, à Linguística e à Semiologia geral, distinguindo-se assim de todas as outras formas de expressão visual.

\section{Os benefícios desse diálogo}

A escrita é considerada como uma semiótica ligada a outras semióticas. Ela possui propriedades internas e tipos de trocas com outras semióticas, como a língua, mas também 
o ritual, a prática. Os signos gráficos podem remeter tanto a um significado linguístico e/ ou não linguístico (ideológico, prático etc.) quanto a ambos, como os exemplos analisados acima nos mostraram. Em outras palavras, a escrita, enquanto semiótica gráfica, é um disparador de transposições intersemióticas do grafismo para uma ou mais práticas da linguagem verbal, bem como para outras práticas associadas. Essa concepção abre perspectivas de diálogos fecundos com a Semiótica estrutural e, em particular, com a problemática dos formantes, segundo seu desenvolvimento por J.-M. Floch (1985): os formantes da escrita, de fato, não apenas são inseparáveis da prática e da técnica de escrita, mas são também o ponto de inflexão entre o valor linguístico dos caracteres e a dimensão icônica do grafismo.

Lembramos que um formante é uma parte da cadeia de expressão correspondente a uma unidade do plano do conteúdo. Há formantes "figurativos", ou seja, formantes constituídos por um dispositivo de expressão ao qual a grade de leitura do mundo natural atribui um significado e que é assim transformado em signo-objeto. Existem também formantes "plásticos", que servem de "pretextos" para investimentos de significação distintos, mais abstratos, geralmente de natureza axiológica e frequentemente em âmbito textual (GREIMAS, 1984).

Tomemos, a título de exemplo, as palavras espaciais da escrita hieroglífica da Anatólia (KLOCK-FONTANILLE, 2011).

\section{कि Em frente \\ ब偻 Atrás \\ $U_{\beta} \quad$ Ao lado de \\ $\uparrow$ Sobre \\ Ds Sob \\ g) Com}

É certo que os sinais dessa série parecem ser caracterizados por uma certa iconicidade: reconhecemos um rosto, um braço. Mas essa iconicidade é enganosa. Na verdade, outros procedimentos estão em jogo aqui. O espaço é organizado a partir de um sujeito: esse situa um objeto em relação a si mesmo, ele é a origem do sistema de referência. O espaço é projetado e produzido por esse sujeito que seleciona e focaliza os objetos dentro dos limites ditados pela sua própria competência. O que caracteriza então esse grupo de signos é a instalação de um centro de referência e de um ponto de vista. 
Assim, "em frente" é constituído por uma cabeça de homem com um traço saindo da boca, à qual une-se o bastão retorcido. O que importa aqui é o sentido do movimento e a linha do olhar: a direção é frontal. O sinal "atrás" é figurativizado por um antebraço dobrado, cercado por um anel: o que é relevante é que o anel esteja por trás. Percebemos aí a instalação de um ponto de vista a partir do sujeito: pouco importa que ele seja representado por um braço ou uma cabeça.

Podemos analisar da mesma maneira "ao lado de", "em direção a": esse sinal associa um primeiro signo (?) a outro que representa um nariz e um olho: a dimensão pertinente é a distância. Observemos os sinais "sobre" e "sob": no primeiro, uma mão apontando para cima, no segundo, uma mão estendida, com um dedo apontando para baixo: o que é relevante aqui é o eixo vertical.

Como podemos ver, os signos tomados isoladamente não apresentam sentido, eles só possuem sentido uns em relação aos outros e essas relações apoiam-se em propriedades plásticas (arranjo no espaço gráfico), e não em propriedades figurativas (cabeça, braço etc.). Assim, é o sistema plástico que deve ser levado em conta como expressão dos conteúdos espaciais.

Mas, sobretudo, podemos ver aqui o que A. J. Greimas havia chamado de fenômenos de desvio: como certos significados postulados durante a leitura figurativa (uma cabeça de homem > significado "homem") são desligados de seus formantes figurativos para servir de significado aos formantes plásticos em vias de construção: alguns traços do significante plástico (em frente/atrás, presença ou ausência de linhas, acima/abaixo) destacam-se ao mesmo tempo dos formantes figurativos onde eles se encontram integrados e, obedecendo aos princípios de organização autônomos do significante, constituem-se em formantes plásticos, suportes de um outro significado. Em outras palavras, além da simples representação, ou seja, além dos conteúdos identificáveis e verbalmente traduzíveis ("plano figurativo"), um objeto visual pode também carregar outros significados através de meios expressivos como as formas, os planos, os enquadres, as linhas e as cores, ou seja, todos os elementos que, postos no suporte planar, constituem os aspectos plásticos da imagem.

Um último exemplo nos permitirá ilustrar a questão da relação entre plano da expressão e plano do conteúdo e, mais precisamente, a ideia de que a escrita, enquanto semiótica gráfica, é um disparador de transposições intersemióticas, do grafismo para uma ou mais práticas da linguagem verbal, bem como para outras práticas associadas. Existem diversas significações (políticas, ideológicas etc.) que se atualizam nas expressões. Tomemos o exemplo de um mito bastante conhecido, a batalha do deus da tempestade e do dragão. Nós o encontramos em muitas culturas, em diferentes épocas e sob gêneros distintos (inscrições, contos, esculturas, petróglifos etc.): Tiamat, derrotado por Marduk na mitologia suméria; Ladão, guardião das maçãs das Hespérides ou o Dragão da Cólquida, guardião do velocino de ouro na mitologia grega; o pilar número 20 do templo de Göbekli Tepe (SCHMIDT, 2015), que representa uma cobra rastejando para baixo de frente 
a um touro, cercados por duas faixas laterais, de modo que o touro, mostrado verticalmente e de perfil, encontra-se face a face com a serpente que vem de cima; e muitos outros: Fafnir e o ouro do Reno, São Jorge e o dragão, a estela dita do "chefe da tribo" no Vallée des Merveilles etc.

Assim, estamos na presença de diversas manifestações da mesma "história": um deus da Tempestade (ou um de seus avatares) é, em um primeiro momento, derrotado por uma serpente-dragão para em seguida vencê-la.

Mas, como dizíamos acima, a escrita não se limita a oferecer uma forma tangível às sequências efêmeras da língua, ela representa, com a língua, aquilo que P. Vernus chama "a reprodução do real ideológico" (1985, p. 63).

Vamos nos deter em duas formas dessa história: o mito de Illuyanka e a estela dita do "chefe da tribo" (Vallée des Merveilles, 3300-1800 a.C.). O primeiro exemplo pertence à mitologia da Anatólia, que apresenta a particularidade de sempre vincular um mito a um ritual.

O mito de Illuyanka (LAROCHE, 1965, p. 5-12) era contado durante a festa de ano novo (em março) e era seguido pela realização de um ritual. O deus da Tempestade é derrotado pelo dragão Illuyanka, que arranca seu coração e seus olhos. Na segunda versão desse mito, o deus da Tempestade se casa com a filha de um mortal, a qual lhe dá um filho. Quando esse cresce, ele se casa com a filha de Illuyanka e recupera o coração e os olhos de seu pai. Na sequência de uma nova batalha, o deus da Tempestade mata Illuyanka (e seu próprio filho). Segue-se o ritual. Essa narrativa está escrita em caracteres cuneiformes em uma tabuleta de argila: a leitura é linear, o alinhamento dos caracteres corresponde ao fluxo da fala.

Examinemos a estela (Fig. 4) dita do "chefe da tribo" (LUMLEY; ECHASSOUX, 2011). Trata-se de um grande composição com um eixo de simetria (os punhais). À esquerda, vemos uma figura antropomórfica, a quem chamamos "chefe da tribo", com os pés para dentro (portanto, uma divindade). Ele é feito de um aglomerado de corniformes. Ele tem os braços estendidos, as mãos abertas, o sexo masculino e um punhal cravado na cabeça. Essa parte da esquerda corresponde, em nossa opinião, ao conto/mito da morte do deus da Tempestade e a parte da direita figurativiza o ritual que deve ressuscitar o deus e trazer água. O deus-touro é incorporado ao deus da Tempestade, que traz a chuva fertilizante. Ele é sacrificado no outono e ressuscitado na primavera.

À direita, podemos ver um grande reticulado que figurativiza os campos cultivados e um pequeno personagem com os pés virados para fora (portanto, um humano), os braços erguidos em pose de oração, sem dúvidas o padre que realiza o ritual. Vemos também espalhados grupos de golpes na rocha, representando a chuva.

Os formantes figurativos apenas passam a significar, por assim dizer, após a aplicação da grade de leitura do mundo natural, mas os formantes plásticos são convocados a servir de pretexto/suporte a investimentos de outros significados. É, então, a organização plástica que permite: 
- de um lado, remeter a outras práticas da linguagem verbal: por exemplo, nesta estela, a oposição esquerda/direita remete à oposição mito/rito;

- de outro lado, encarregar-se de diferentes visões de mundo, valores culturais, políticos etc.: o dragão que detém a água e a impede de cair (a vitória contra o deus da Tempestade) pertence a culturas camponesas, nas quais a água é um bem precioso. Outra série liga o dragão a tesouros, ele é o dragão guardião do tesouro nas sociedades onde o marco dos valores não é mais água, mas riqueza. Pensemos no Dragão da Cólquida que guarda o velocino de ouro, em Ladão que guarda as maçãs de ouro do jardim das Hespérides, ou ainda em Fafnir, guardião do ouro do Reno. Enfim, o dragão é "moralizado" como símbolo do mal nas sociedades investidas de valores judaico-cristãos (São Jorge, o bastião do bem).

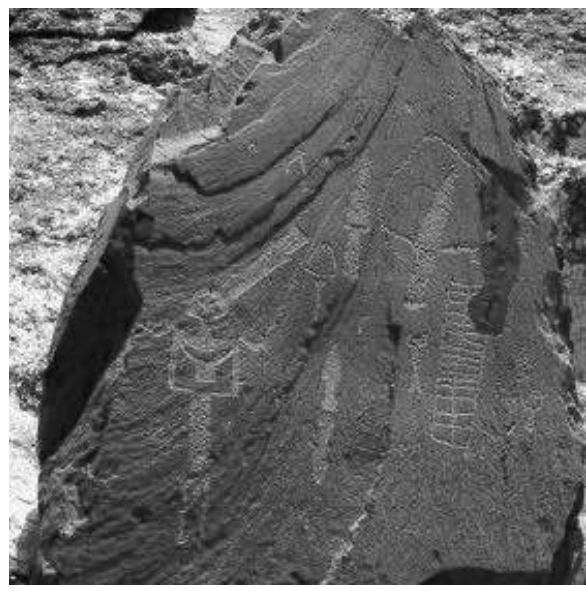

Fig. 4. A estela do chefe da tribo. Fonte: https://www.pinterest.fr/pin/560276009865925454/.

Alguns poderiam pensar que a estela que escolhemos não é "escrita". Na verdade, questionar se esse conjunto de signos pode ser considerado como uma escrita não é uma boa pergunta. Isso seria aderir à concepção da "visão representativa da escrita", que corresponde também, como lembramos, àquela que reduz a escrita à escrita alfabética. Pensamos que a distinção tradicional entre "proto-escritas" próximas de imagens (que não seriam verdadeiros sistemas de escrita) e escritas dependentes da língua não é pertinente e que a escrita é uma transcrição de processos cognitivos, não apenas e não necessariamente da língua (KLOCK-FONTANILLE, 2016b).

Esse tipo de composição corresponde bem a um texto e, de fato, estamos na presença de um sistema gráfico. Mas, evidentemente, cada signo não equivale a uma letra ou a uma palavra, como é o caso em nossa escrita alfabética. É toda a composição que 
remete a um provável significado linguístico - ao qual não temos acesso - mas, sobretudo, a um significado não-linguístico (a uma prática, a um rito). As escritas são organizações de expressão visual e plástica disponíveis a qualquer tipo de conteúdo.

\section{Conclusão}

Começamos nosso estudo relembrando que a pesquisa sobre as escritas havia permanecido tempo demais subordinada à Linguística, como uma espécie de "parente pobre" dessa disciplina. Isso resultou em uma concepção representativa simplista, na qual a escrita se encontrava submetida à língua. Na França, ficamos muito tempo presos a esse confronto com a Linguística ou, mais precisamente, com uma vulgata vinda da tradição saussuriana. Quando essa posição se tornou insustentável, a vontade de redefinir o signo escrito e autonomizar o escritural foi alcançada pela abertura a outras disciplinas. Um diálogo pôde ser instaurado entre Linguística, Semiótica e Antropologia, em que a Semiótica não era apenas um simples parceiro. De fato, ela foi o "chefe de obras" natural e a interface entre as disciplinas, graças à sua tripla base fundadora (Linguística, Antropologia, Fenomenologia).

Traduzido por Marc Barreto Bogo.

Isabelle Klock-Fontanille é pesquisadora do CeReS, na Université de Limoges \& IUF.

\section{Referências}

ARISTOTE. De I'interprétation. Trad. J. Tricot. Paris: Vrin, 1936. [Ed. em português: ARISTÓTELES. Da interpretação. Trad. e comentários José Veríssimo Teixeira da Mata. São Paulo: UNESP, 2013].

BATTESTINI, S. Écriture et texte: contribution africaine. Québec: Presses de l'Université Laval, 1997.

De l'écrit africain à l'oral. Paris: L'Harmattan, 2006.

Dernières leçons: Collège de France 1968 et 1969. Paris: EHESS/Seuil/Gallimard, 2012. [Ed. citada em português: BENVENISTE, É. Últimas aulas no Collège de France (1968 e 1969). Trad. Daniel Costa da Silva et al. São Paulo: Editora Unesp, 2014].

CALAME-GRIAULE, G.; LACROIX, P.-F. Graphies et signes africains. Semiotica, I (3), p. 256-272, 1969. CARDONA, G. R. Antropologia della scrittura. Torino: Loescher, 1981.

FEVRIER, J. Histoire de l'écriture. Paris: Payot, 1959.

FLOCH, J. Petites mythologies de l'œil et de l'esprit. Paris/Amsterdam: Hadès/Benjamins, 1985.

GELB, I. J. A Study of Writing. Chicago/London: The University of Chicago Press, [1952] 1973. [Ed. em francês: GELB, Ignace J. Pour une théorie de l'écriture. Paris: Flammarion, 1973]. 
GLASSNER, J. Écrire à Sumer: I'invention du cunéiforme. Paris: Seuil, 2000.

GREIMAS, A. J. Sémiotique figurative et sémiotique plastique. Actes sémiotiques - Documents, VI, 60, 1984. [Ed. citada em português: GREIMAS, A. J. Semiótica figurativa e semiótica plástica. Trad. I. Assis Silva. Significação - Revista Brasileira de Semiótica, n. 4, p. 18-46, 1984].

HARRIS, R. The origin of writing. London: Duckworth, 1986.

Sémiologie de l'écriture. Paris: CNRS Éditions, 1993.

Théorie de l'écriture: une approche intégrationnelle. Op. Cit. revue de littérature française et comparée, n. 10, p. 15-18, 1998.

KLOCK-FONTANILLE, I. L'écriture hiéroglyphique hittito-louvite: une écriture publique au service du pouvoir. Temporalités, n. 3, p. 17-36, 2006.

. L'écriture de l'espace: la perception de l'espace dans l'écriture hiéroglyphique anatolienne. Altorientalische Forschungen, v. 38, p. 199-212, 2011.

Présentation du dossier. In: KLOCK-FONTANILLE, Isabelle (Ed.). Actes Sémiotiques, n. 119: Écriture(s), 2016a. 2016b.

Repenser l'écriture: pour une grammatologie intégrationnelle. Actes Sémiotiques, n. 119,

KRÄMER, S. Notational iconicity, calculus: On writing as a cultural technique. MLN, v. 118, n. 3, p. 518-537, 2003a.

. "Schriftbildlichkeit" oder: Über eine (fast) vergessene dimension der schrift. In: BREDEKEMP, H.; KRÄMER, S. (Eds.). Bildschrift - Zahl. München: Fink Verlag, p. 157-176, 2003 b.

Entre discursivité et iconicité, un nouveau regard sur les écritures. Actes Sémiotiques, n. $119,2016$.

LAROCHE, E. Textes mythologiques hittites en transcription. Paris: Klincksieck, 1965.

LESSING, G. E. Laocoon ou des frontières respectives de la peinture et de la poésie. Trad. F. Teinturier. Paris: Klincksieck, [1766] 2011.

LUMLEY, H. de; ECHASSOUX, Annie. La montagne sacrée du Bego. Paris: Éditions du CNRS, 2011.

Scrittura, percezione e cultura: qualche riflessione sull'Anatolia in età Hittita. KASKAL, v. 7, p. 219-255, 2010.

MARAZZI, M. Le relazioni fra lingua e scrittura nelle civiltà dello spazio iscritto. Actes Sémiotiques, n. 119, 2016.

PERRI, A. Evento linguistico vs evento scrittorio: verso un nuovo modello. Rivista di Psicolinguistica Applicata, ano VII/2, p. 125-145, 2007.

PERRI, A. Why writing is not (only) transcribing? Writing codes in contact: steps towards multigraphic literacy practices. Testo e senso, n. 15, p. 75-98, 2014.

SAUSSURE, F. de. Cours de linguistique générale. Paris: Payot, 1986. [Ed. citada em português: SAUSSURE, F. de. Curso de linguística geral. 27.ed. Orgs. Charles Bally, Albert Sechehaye; colab. Albert Riedlinger; prefácio Isaac Nicolau Salum; trads. Antonio Chelini, Jose Paulo Paes, Izidoro Blikstein. São Paulo: Cultrix, 2006].

SCHMIDT, K. Le premier temple: Göbekli Tepe. Paris: CNRS Éditions, 2015.

SEVERI, C. Paroles durables, écritures perdues: réflexions sur la pictographie cuña. In: DETIENNE, M. (Ed.). Transcrire les mythologies. Paris: Albin Michel, p. 45-76, 1994. 
VERNUS, P. Espace et idéologie dans l'écriture égyptienne. In: CHRISTIN, A.-M. (Ed.). Écritures, systèmes idéographiques et pratiques expressives. Paris: Le Sycomore, p. 101-114, 1982.

Des relations entre textes et représentations dans I'Égypte pharaonique. In: CHRISTIN, A.-M. (Ed.). Écritures II. Paris: Le Sycomore, p. 45-69, 1985.

L'ambivalence du signe graphique dans l'écriture hiéroglyphique. In: CHRISTIN, A.-M. (Ed.). Écritures III. Paris: Retz, p. 60-65, 1988.

De l'image au signe d'écriture, du signe d'écriture à l'image, de l'image au signe d'écriture: la ronde sémiotique de la civilisation pharaonique. Actes Sémiotiques, n. 119, 2016.

Artigo recebido em 29/05/2020

e aprovado em 20/07/2020. 